\title{
Primate Models for Australopithecine Sexual Dimorphism ${ }^{1}$
}

\author{
MILFORD H. WOLPOFF \\ Department of Anthropology, University of Michigan, Ann Arbor, \\ Michigan 48109
}

KEY WORDS Australopithecine - Sexual dimorphism $\cdot$ Hominid evolution Pongid evolution.

\begin{abstract}
Several different models of sexual dimorphism in the South African australopithecines are compared with sexual dimorphism in the living primates. Australopithecine dimorphism is placed in an evolutionary context, and contrasting trends in the hominid and pongid lineages are shown. Evidence suggesting that the australopithecines were an extremely polytypic taxon is presented, and a high level of both inter- and intra-population variation is indicated.
\end{abstract}

The evolution of sexual dimorphism has received little attention in recent decades, although it seemed of great importance before a substantial fossil record had been discovered (Bonnet, '19). Yet the extent of the fossil record currently known, and the large available body of knowledge concerning the living non-human primates, suggest that an understanding of the evolution of this phenomenon is of particularly critical importance both for its own sake, and as a possible explanation for the considerable amount of individual variability that seems to characterize almost every known fossil hominid site with more than one individual (Brace, '73).

Of course, many attempts have been made to determine the sex of individual fossils as they are discovered. Few, however, have sought to understand the general pattern of evolution of the phenomenon in the hominid lineage. Furthermore, several recent attempts to arrive at such an understanding have been confused by various misstatements of sexual dimorphism hypotheses concerning the Pliocene and Lower Pleistocene hominids. This early sample comprises the first clearly recognizable group of human ancestors. An unambiguous determination of their sexual dimorphism is crucial in both tracing the evolution of the phenomenon and in help- ing to partition the causes of variation within the early hominid sample itself.

The purpose of this work is to discuss various models of early hominid sexual dimorphism; to present an unambiguous model for sex determination in the early hominids and determine the degree of sexual dimorphism in the sample; and to place the sexual dimorphism established in an evolutionary context.

\section{TESTING THE NON-HYPOTHESIS}

In a recent publication, the non-hypothesis that the South African gracile australopithecines are females, and the South African robust australopithecines are males, has been once again resuscitated (Greene, '73). This contention has been stated by numerous authors (Holloway, '70; Pilbeam, '72; Robinson and Steudel, '73; and an anonymous Nature editorial (228: p. $315)$, and considerable effort has been expended in its "refutation." However, an examination of the sources usually quoted as originating the "hypothesis" (Brace, '69; Brace et al., '71; Wolpoff, '71) reveals that the contention exists in only the publications of the quoters. The quotees have found it necessary to reiterate their position on several different occasions (Brace,

\footnotetext{
${ }^{1}$ Supported in part by NSF Grant GS-33035.
} 
'73; Wolpoff, '75) and this will hopefully be the last time it is necessary.

Greene has chosen to test the "hypothesis" that "the differences between Paranthropus and Australopithecus are no greater than those found between male and female gorilla," explicitly quoting Brace ("71) as its source although what Brace actually said was:

"Within group variation in the Australopithecines is comparable to the variation in modern primates where sexual dimorphism is large." (p. 274)

Greene's approach to testing the non-hypothesis is to establish the degree of sexual dimorphism in gorillas, and several modern human groups, and then to determine whether the difference between the australopithecine samples exceeds this.

A modification of a test statistic suggested by Spiegel ('61) is used for this purpose:

where

$$
t=\frac{\left(\bar{x}_{p}-\bar{x}_{a}\right)-\left(p_{\delta}-p_{\rho}\right)}{\sqrt{\frac{\sigma_{\sigma}^{2}}{n_{p}}+\frac{\sigma_{\rho}^{2}}{n_{a}}}}
$$

$\overline{\mathrm{X}}_{\mathrm{p}}=$ Paranthropus mean

$\overline{\mathrm{X}}_{\mathrm{a}}=$ Australopithecus mean

$\mu_{\delta}=$ mean of male primate tested against

$\mu_{\rho}=$ mean of female primate tested against

$\sigma_{\delta}=$ mean of male primate standard deviation

$\sigma_{Q}=$ female primate standard deviation

$\mathrm{n}_{\mathrm{p}}=$ size of the Paranthropus sample

$n_{\mathrm{a}}=$ size of the Australopithecus sample

and the expected distribution is that of a single tailed student's $t$. To begin with, it is far from obvious that this test is appropriate. This can be seen when considering its behavior at the extremes. For instance, if the teeth of male gibbons were twice the size of female gibbons, and the teeth of male gorillas were twice the size of female gorillas, by any reasonable interpretation, one would conclude that these two higher primate species had the same degree of sexual dimorphism. Yet if this test were used, it would "demonstrate" that the sexual dimorphism in the two species was completely different. This problem must occur whenever two species with different sized teeth are compared, since the test depends on a comparison of absolute size difference. Given the fact that the postcanine teeth of the smaller australopithecine sample are between two and three times larger than those of living humans (Wolpoff, "73), the tests comparing australopithecines and humans are at best misleading. The comparison with male and female gorillas may be more appropriate, since australopithecine postcanine teeth fall fully within the gorilla range of variation.

For this reason, I attempted to test the non-hypothesis myself, using the very large gorilla sample made available by Mahler (73), and the measurements I took on all of the South African australopithecine specimens. The data for the test statistics are given in tables 1 and 2 .

The maxilla alone was used for these comparisons. Greene uses only the postcanine teeth, but includes both jaws, raising an additional problem because of the difference in function in the lower third premolar. Use of the maxilla alone seemed to be a better choice because only one of the teeth (the canine) has an obviously different function, and since the sample size of maxillary teeth is larger than the mandibular sample in the South African australopithecines. Only breadths of the incisors are considered because there are virtually no unworn incisors and the immediate effect of wear is to reduce the mesiodistal length of these teeth. Breadth is reported for the canines, and the comparison uses areas for the canine and postcanine dentition. No comparisons involving a sample size of less than four are reported. My own feeling is that any sample smaller than at least ten should be considered suspect, although if such comparisons are also eliminated virtually nothing is left to compare. The point is that with samples this small, the pattern becomes more important than each individual tooth comparison.

The statistic is calculated for all of the samples shown in table 2, with the gorilla sample (table 1) used as a base. The significance of the $t$ is determined, using the 
TABLE 1

Male and female means and standard deviations for gorilla and baboon samples

\begin{tabular}{|c|c|c|c|c|c|c|c|c|}
\hline & \multicolumn{4}{|c|}{ Gorilla } & \multicolumn{4}{|c|}{ Baboon } \\
\hline & \multicolumn{2}{|c|}{ Male } & \multicolumn{2}{|c|}{ Female } & \multicolumn{2}{|c|}{ Male } & \multicolumn{2}{|c|}{ Female } \\
\hline & $\overline{\bar{x}}$ & $\sigma$ & $\overline{\mathbf{x}}$ & o & $\overline{\mathrm{x}}$ & 0 & $\overline{\mathrm{x}}$ & 0 \\
\hline \multicolumn{9}{|c|}{ Breadth $(\mathrm{mm})$} \\
\hline $\mathrm{I}^{2}$ & 10.10 & .92 & 8.99 & .81 & & & & \\
\hline $\mathrm{C}$ & 16.13 & 1.80 & 11.45 & .91 & & & & \\
\hline \multicolumn{9}{|c|}{ Area $\left(\mathrm{mm}^{2}\right)$} \\
\hline $\mathrm{C}$ & 346.2 & 56.5 & 168.1 & 22.3 & 136.3 & 30.1 & 52.9 & 10.1 \\
\hline $\mathbf{P}^{3}$ & 182.8 & 23.3 & 159.7 & 17.5 & 55.9 & 11.1 & 44.6 & 11.0 \\
\hline $\mathrm{P}^{4}$ & 168.9 & 18.4 & 150.6 & 16.0 & 69.1 & 13.3 & 58.2 & 12.5 \\
\hline $\mathbf{M}^{1}$ & 232.5 & 24.6 & 209.2 & 20.8 & 107.6 & 18.3 & 89.7 & 17.5 \\
\hline $\mathbf{M}^{2}$ & 268.9 & 31.9 & 235.9 & 26.3 & 149.9 & 20.8 & 124.6 & 22.8 \\
\hline $\mathbf{M}^{3}$ & 236.8 & 30.3 & 199.6 & 27.0 & 152.6 & 21.4 & 123.3 & 25.9 \\
\hline
\end{tabular}

The gorilla data are from Mahler ('73) and the sample sizes are all large. Male sample sizes range from 197 ([2) to $262\left(\mathrm{M}^{1}\right)$, and the females from $114\left(\mathrm{I}^{2}\right)$ to $149\left(\mathrm{P}^{3}, \mathrm{M}^{2}\right)$. The baboon data are from Lauer ('75), and represent a sample of 30 male and 18 female specimens. The choice of teeth used corresponds to the data in table 2 .

TABLE 2

Data for the australopithecine sample from South Africa, for comparison with the primate data given in table 1 and calculation of the test statistic

\begin{tabular}{|c|c|c|c|c|c|c|c|c|c|c|c|c|c|c|c|c|}
\hline & \multirow{2}{*}{\multicolumn{2}{|c|}{ Robust }} & \multirow{2}{*}{\multicolumn{2}{|c|}{ Gracile }} & \multicolumn{4}{|c|}{ Gracile } & \multicolumn{4}{|c|}{ Hobust } & \multicolumn{4}{|c|}{ Combined Sample } \\
\hline & & & & & \multicolumn{2}{|c|}{ Male } & \multicolumn{2}{|c|}{ Fernale } & \multicolumn{2}{|c|}{ Male } & \multicolumn{2}{|c|}{ Female } & \multicolumn{2}{|l|}{ Male } & \multicolumn{2}{|c|}{ Female } \\
\hline & $\overline{\mathrm{x}}$ & $\mathbf{n}$ & $\bar{x}$ & $\mathrm{n}$ & $\overline{\mathbf{x}}$ & $\mathbf{n}$ & $\overline{\mathrm{x}}$ & $\mathrm{n}$ & $\overline{\mathrm{x}}$ & $n$ & $\overline{\mathrm{x}}$ & $\mathrm{n}$ & $\overline{\mathrm{x}}$ & $\mathrm{n}$ & $\overline{\mathrm{x}}$ & $\mathrm{n}$ \\
\hline \multicolumn{17}{|c|}{ Breadth (mm) } \\
\hline$I^{2}$ & 7.01 & 9 & 6.58 & 6 & & & & & & & & & 7.15 & 4 & 6.48 & 5 \\
\hline $\mathrm{C}$ & 9.78 & 19 & 9.56 & 17 & 10.6 & 6 & 9.0 & 11 & 10.6 & 9 & 9.1 & 10 & 10.6 & 15 & 9.0 & 21 \\
\hline \multicolumn{17}{|c|}{ Area $(\mathrm{mm})^{2}$} \\
\hline $\mathrm{C}$ & 86.9 & 13 & 92.1 & 7 & & & & & 99.3 & 5 & 79.1 & 8 & 102.7 & 7 & 81.2 & 13 \\
\hline $\mathrm{P}^{3}$ & 132.3 & 22 & 112.7 & 15 & 116.0 & 5 & 112.0 & 4 & 131.3 & 7 & 120.1 & 7 & 124.9 & 12 & 117.1 & 11 \\
\hline $\mathrm{P}^{4}$ & 151.9 & 30 & 120.2 & 13 & 132.9 & 4 & 112.5 & 4 & 162.1 & 7 & 137.5 & 7 & 151.5 & 11 & 128.4 & 11 \\
\hline $\mathbf{M}^{1}$ & 193.8 & 33 & 176.5 & 21 & 182.9 & 5 & 163.3 & 5 & 206.7 & 7 & 173.8 & 7 & 196.8 & 12 & 169.4 & 12 \\
\hline $\mathbf{M}^{2}$ & 224.0 & 20 & 222.4 & 20 & 237.3 & 5 & 205.2 & 5 & 229.8 & 5 & 199.0 & 4 & 233.5 & 10 & 202.4 & 9 \\
\hline $\mathbf{M}^{3}$ & 228.8 & 22 & 227.4 & 17 & & & & & 253.7 & 4 & 200.4 & 4 & 233.3 & 7 & 196.4 & 7 \\
\hline
\end{tabular}

All data are from measurements made on the original specimens by the author. The first two columns give means and sample sizes for the gracile (i.e., Sterkfontein, Makapan, and Taung) and robust (i.e., Swartkrans and Kromdraai) samples in order to test Greene's nonhypothesis. The remaining columns give means and sample sizes for likely males and females of the gracile sample alone, the robust sample alone, and the combined sample (for criteria of sexing, see text). No sample of less than four is reported.

single tailed assumption, and the results are shown in table 3 . The test of the nonhypothesis is indicated in column 1 .

The only tooth dimension larger in the gracile sample than in the robust one is the area of the canine, although a student's $t$ shows the difference is not significant on the $5 \%$ level. When the canine breadth is used, the robust sample has the larger average size. The canine breadth sample size is much larger since it includes socket dimensions; the breadth of an undistorted socket is an extremely good indicator of crown breadth in the australopithecines. I verified this by measuring both crown and socket breadths when both were available. The regression slope between them is not significantly different from 1 . Is the breadth measurement a better indication of the difference between these samples because of the larger sample size, or is the difference between the breadth and area comparisons due to an average shape difference? Actually, there is an average 
TABLE 3

Results of the test statistic, comparing sexual dimorphism in the gorilla sample reported in table 1 with the various comparisons shown in table 2

\begin{tabular}{|c|c|c|c|c|}
\hline & Gracile/robust & $\begin{array}{c}\text { Gracile } \\
\text { F/M }\end{array}$ & $\begin{array}{c}\text { Robust } \\
\text { F/M }\end{array}$ & $\begin{array}{l}\text { Combined } \\
\text { F/M }\end{array}$ \\
\hline \multicolumn{5}{|c|}{$\begin{array}{l}\text { Brcadth } \\
\text { I }^{2}\end{array}$} \\
\hline $\mathrm{C}$ & - & - & - & - \\
\hline \multicolumn{5}{|c|}{ Area } \\
\hline $\begin{array}{l}\mathrm{C} \\
\mathrm{P}^{3}\end{array}$ & 1 & & - & - \\
\hline $\mathrm{P}^{4}$ & + & & & \\
\hline $\mathrm{M}^{1}$ & & & & \\
\hline $\mathbf{M}^{2}$ & - & & & \\
\hline $\mathbf{M}^{3}$ & - & & & \\
\hline
\end{tabular}

Only in the cases in which the differences are significant on the $5 \%$ level are indicated. $A$ " + " means that the Lower Pleistocene hominid comparison shows a greater difference than the respective male/female gorilla difference, while a " - " shows that this difference is significantly less. In all other cases, there is no significance to the difference indicated.

${ }^{1}$ Gracile $>$ robust.

shape difference between the two samples. The index of canine length to canine breadth is $96.4 \%$ in the gracile sample, and $92.4 \%$ in the robusts. However, this does not account for the difference in breadth and area comparisons. Thus, if this index is used to "predict" lengths for the specimens having only a breadth measurement, and area is calculated, the average areas for gracile and robust samples are respectively $88.1 \mathrm{~mm}^{2}$ and $88.3 \mathrm{~mm}^{2}$. The most reasonable conclusion is that there is no significant difference between them.

For canine breadth, and for all but one of the remaining teeth shown, the australopithecine variation (e.g., graciles compared with robusts) is less than the variation between female and male gorillas. In three of the comparisons, the difference is significant on the $5 \%$ level. The pattern of comparisons, then, rather clearly suggests that the non-hypothesis cannot be refuted, and that the gracile-robust comparison is generally less than the female-male comparison. The single exception is $\mathrm{P}^{4}$, where the difference is significantly greater. I am not certain why these results differ from Greene's, although the solution is probably in the fact that both the gorilla and the australopithecine samples are much larger than those used in his comparisons. In any event, if an author were to seriously propose that the robust australopithecines were males, and the graciles were females, and that they showed no greater dimorphism than gorilla males and females, the available data would not clearly refute this contention.

\section{TESTING THE HYPOTHESIS}

The hypothesis which $I$, as well as others, would support was succinctly stated by Brace. We believe that the degree of sexual dimorphism in these Pliocene and Lower Pleistocene fossil hominids is greater than that in living hominids, and consequently their population variation is greater. While variability can be compared directly on the species level, there is no way to distinguish biological populations of fossil hominids. Consequently, there is no direct way to compare population variability.

Fortunately, however, sexual dimorphism apparently can be determined and compared, because it seems possible to correctly sex many of the Lower Pleistocene hominid specimens (Wolpoff, '75). Dental remains of the australopithecines outnumber all other remains combined, and could potentially provide a useful sexing criterion. There are only two associations of pelvis and cranium, and only a very few associated dentitions and relatively complete crania. In living humans, as in most higher primates, the canine shows the greatest sexual dimorphism of any single tooth (Gonda, '59). Since the mesiodistal diameter of the canine can be affected by interproximal wear (Wolpoff, '71), the labiolingual diameter (breadth) would be expected to show the clearest dimorphism. In a review of eight populational studies (Wolpoff, '75), I showed that the breadth of the canine has the greatest dimorphism five out of eight times in the maxilla, and six out of eight times in the mandible. Moreover, when the average dimorphism in the eight populations is considered, the canine is the most dimorphic tooth. Unlike most other higher primates, however, the frequency distributions of canine breadth in living human populations are unimodal 
(Misberg, '31) and show extensive overlap between the sexes (Garn et al., '64, '66), although it is rare for a male canine to fall below the female mean, and for a female canine to fall above the male mean. This is difficult to show from published studies, since only the extremes of the ranges are usually given. In a population sample of Libben Amerinds from northeast Ohio, sexed on the basis of the pubis, only two out of $\mathbf{4 4}$ male maxillary canines fall below the female mean, and one out of 33 female canines is larger than the male mean. For the mandible, two out of 30 male canines fall below the female mean, while one out of 23 female canines exceeds the male mean. Therefore, in living humans, even the best dental measure of sexual dimorphism results in considerable ambiguity if an attempt is made to sex individual specimens.

In contrast, the frequency distributions of canine breadth in gorillas and baboons are bimodal. There is virtually no overlap between the male and female distributions, and an attempt to use canine breadth to sex individual specimens would be extremely accurate.

While the "true" sexes of the australopithecine specimens remain unknown, it is interesting that when the South African sample is used as an example of a geographically limited set, the frequency distribution of canine breadths appears strongly bimodal, with virtually no overlap between the modes (table 4). The bimodality occurs whether the South African samples are broken into gracile and robust groups, or considered all together. Furthermore, it characterizes both the maxillary canines, shown here, and the mandibular distribution as well (Wolpoff, '75). The few specimens with both mandibular and maxillary canine breadths fall in the same mode for both jaws. That is, if the maxillary canine is in the small mode the mandibular canine will also be in the small mode.

While no test establishes bimodality, it is possible to determine whether the canine breadth distribution is normal. The frequencies for a normal distribution with the
TABLE 4

Frequency distribution, in absolute numbers, of the South African australopithecine canine breadths

\begin{tabular}{c} 
Canine \\
$\begin{array}{c}\text { breadth } \\
\text { (mm) }\end{array}$ \\
\hline
\end{tabular}

A. Cumulative frequency distribution

$\begin{array}{llll}8.0 & 0 & 1 & 1\end{array}$

8.1

8.2

8.3

8.4

8.5

8.6

8.7

8.8

8.9

9.0

9.1

9.2

9.3

9.4

9.5

9.6

9.7

9.8

9.9

10.0

10.1

10.2

10.3

I0.4

10.5

10.6

10.7

10.8

10.9

11.0

11.1

11.2

11.3

11.4

11.5

11.6

11.7

11.8

11.9

12.0

12.1

$\begin{array}{lll}0 & 1 & 1 \\ 0 & 1 & 1 \\ 0 & 1 & 1 \\ 1 & 1 & 2\end{array}$

1

1

2

2

2

4

5

8

8

9

9

9

10

10

10

10

1

2

23

2

3

46

59

$7 \quad 12$

7

$8 \quad 17$

$8 \quad 17$

$12 \quad 21$

$12 \quad 22$

$12 \quad 22$

$12 \quad 29$

$12 \quad 22$

$12 \quad 23$

$14 \quad 26$

$15 \quad 28$

$16 \quad 31$

$16 \quad 31$

$17 \quad 32$

$18 \quad 33$

$19 \quad 34$

$19 \quad 34$

$19 \quad 34$

$19 \quad 34$

$19 \quad 35$

$19 \quad 35$

$19 \quad 35$

$19 \quad 35$

$20 \quad 36$

$\begin{array}{lll}16 & 20 & 36 \\ 16 & 20 & 36\end{array}$

$\begin{array}{lll}16 & 20 & 36\end{array}$

$\begin{array}{lll}16 & 20 & 36\end{array}$

$16 \quad 20 \quad 36$

$\begin{array}{lll}16 & 21 & 37\end{array}$

$\begin{array}{lll}17 & 21 & 38\end{array}$

$8.0-8.4$

B. Frequency distribution

$\begin{array}{lll}1 & 2 & 3\end{array}$

$8.5-8.9 \quad 4 \quad 50$

$\begin{array}{llll}9.0-9.4 & 4 & 5 & 9\end{array}$

$\begin{array}{llll}9.5-9.9 & 2 & 0 & 2\end{array}$

$\begin{array}{llll}10.0-10.4 & 4 & 5 & 9\end{array}$

$\begin{array}{llll}10.5-10.9 & 0 & 2 & 2\end{array}$

$\begin{array}{llll}11.0-11.4 & 1 & 1 & 2\end{array}$

$\begin{array}{llll}11.5-11.9 & 0 & 0 & 0\end{array}$

$\begin{array}{llll}12.0-12.4 & 1 & 1 & 2\end{array}$

Gracile and robust samples are considered separately, and combined. 
same sample size, mean, and variance were determined, and a chi-square test was used to compare the two distributions. These were significantly different at the $5 \%$ level. Consequently, one must conclude that the australopithecine maxillary canine breadth distribution is, in all likelihood, not normal. This greatly strengthens the contention that the distribution is what it appears to be: bimodal.

Either these australopithecine bimodal distributions are spurious and due to chance or they are the result of an underlying biological cause. I believe it is unlikely that the bimodal distributions are due to chance for a number of reasons. First, whatever the odds are against sampling a bimodal distribution out of a unimodal underlying distribution, the odds are multiplicative against getting both jaws with bimodal distributions. The samples are virtually completely independent: only three specimens are known to have both maxillary and mandibular canines. Thus, if the odds were one out of ten against a bimodal sample drawn from a unimodal distribution (and chi-square shows that one out of ten is too high), the chances of picking two independent bimodal samples (mandible and maxilla) would be one out of one hundred. Second, if the bimodality in the combined sample were spurious, it would be unlikely that bimodality occurring in the separate smaller sample sets would be exactly the same. Third, sampling the Neandertal distribution is an analogous case allowing an interesting comparison. The sample size is quite similar and the Neandertal sample consists of individuals widespread in both time and space. Yet the Neandertal sample is clearly unimodal (Wolpoff, '75). Fourth, if the separate modes are taken to indicate sex, and if mean values are calculated for each mode, the "male-female" ratios for maxilla and mandible are almost identical, as is true for other primate samples. Because the samples are independent, this would be very unlikely if the bimodal distributions in mandible and maxilla were attributable to chance. The resemblance to patterns known to be due to sexual dimor- phism extends to small detail. For instance, in almost all higher primates, the malefemale ratio in the mandible is equal to or slightly greater than the maxillary ratio. The mandibular ratio in the australopithecines is slightly greater. Fifth, there is no evidence that the bimodality is sitespecific. That is, one site is not contributing most of one mode while another contributes the majority of specimens in the other. Thus, the bimodality does not result from combined distribution of different but overlapping samples of "taxa." The chances of all these factors occurring together are phenomenally low unless there is an underlying biological reason for the australopithecine distribution. Therefore, I believe that the australopithecines follow the pattern provided by all other higher primates, including living humans, in that the canine breadth distribution is the result of sexual dimorphism. The fact that the australopithecine distribution is clearly bimodal allows most of the specimens with canines or undistorted canine sockets to be sexed unambiguously (fig. 1).

Since many specimens can be sexed, it is possible to establish the degree of sexual dimorphism in the dentition, and therefore to test the hypothesis that sexual dimorphism in the australopithecines exceeds that in living humans, and rather follows the more typical terrestrial higher primate pattern.

In table 2, average tooth sizes for the sexable australopithecine specimens are reported, both separately for the gracile and robust samples and for the combined

Fig. 1 Comparison of a male and female palate from Swartkrans. (A) SK 83 (left) is considered male, and (B) SK 48 is considered female on the basis of absolute canine breadth, in spite of the low sagittal crest found on SK 48. While sagittal crests are commonly found with males in primates such as gorillas, females with crests are not unknown. That cresting is somewhat indicative of sex is due to the fact that crests result from the relation of the jaw musculature and cranial size (Wolpoff, 74). Note that both absolute and relative canine sizes contrast these specimens. SK 83 has an absolute and relative canine size that falls near the top of the gracile australopithecine distribution (Tobias, '67; Wolpoff, '73) 


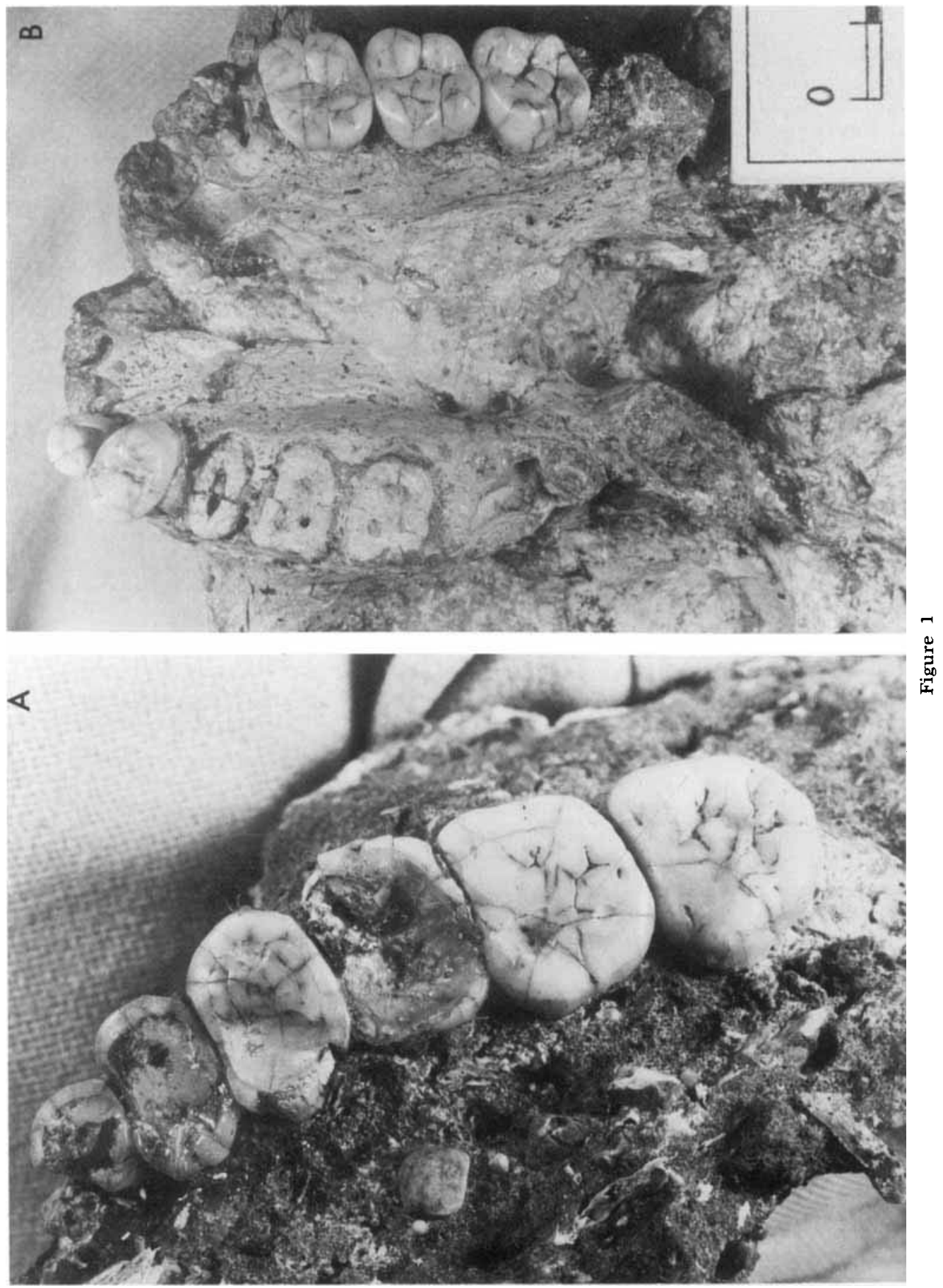


TABLE 5

\begin{tabular}{ccccccc}
\multicolumn{7}{c}{ Indexes of mean values } \\
\hline & $\begin{array}{c}\text { Gracilef } \\
\text { robust }\end{array}$ & $\begin{array}{c}\text { Gracile } \\
\text { F/M }\end{array}$ & $\begin{array}{c}\text { Robust } \\
\text { F/M }\end{array}$ & $\begin{array}{c}\text { Combined } \\
\text { sample } \\
\text { F/M }\end{array}$ & $\begin{array}{c}\text { Gorilla } \\
\text { F/M }\end{array}$ & $\begin{array}{c}\text { Baboon } \\
\text { F/M }\end{array}$ \\
\hline $\begin{array}{c}\text { Breadth } \\
\text { I }\end{array}$ & 93.9 & & & 90.6 & 89.0 & \\
C & 97.8 & 84.9 & 85.8 & 84.9 & 71.0 & \\
Area & & & & & & \\
C & 106.0 & & 79.7 & 79.1 & 48.6 & 38.8 \\
$P^{3}$ & 85.2 & 96.6 & 91.5 & 93.8 & 87.4 & 79.8 \\
P $^{4}$ & 79.1 & 84.7 & 84.8 & 84.8 & 89.1 & 84.2 \\
M $^{1}$ & 91.1 & 89.3 & 84.0 & 86.1 & 90.0 & 83.4 \\
M $^{2}$ & 99.3 & 86.5 & 86.6 & 86.7 & 87.7 & 83.1 \\
M $^{3}$ & 99.4 & & 79.0 & 84.2 & 84.3 & 80.8 \\
\hline
\end{tabular}

The table shows the mean values of gracile and robust australopithecines (column 1), and female and male means for the various australopithecine samples as well as for gorillas and baboons. The index is calculated by the first mean multiplied by 100 and divided by the second mean.

South African sample. As before, no samples of less than four are considered. Because of the similarity in tooth size, Greene's test statistic can be calculated, comparing australopithecine to gorilla dimorphism. The results (table 3) indicate no significant difference at the $5 \%$ level for most of the posterior tooth comparisons. The anterior tooth comparisons show a number of significant differences, and in every case when the difference is significant the australopithecine dimorphism is less than the gorilla dimorphism. These data suggest that the amount of dimorphism in the australopithecines is no less than gorillas in the posterior maxillary dentition, and is significantly less than gorillas towards the front.

Unfortunately, the test statistic cannot be used comparing australopithecine dimorphism with that of living humans or of baboons: the difference in average tooth size is too great. However, it is possible to compare the ratios of male and female means. Although a test of significance for the ratios is not possible, the pattern seems rather clear.

Table 5 shows the australopithecine ratios, and provides gorilla and baboon ratios for comparison. The first column gives data for the non-hypothesis, indicating (as Greene suggested) a pattern of "dimorphism" unlike that of any other living primate: only the premolars show significant "dimorphism." When the actual sexed australopithecine samples are compared, the pattern becomes more similar to that of other primates, and the separate gracile and robust patterns are virtually identical to each other. Canine dimorphism is much less than in either gorillas or baboons, and there is little $\mathrm{P}^{3}$ dimorphism compared with the great amount of dimorphism in $\mathrm{P}^{4}$. The anterior molars show the least dimorphism of the three, while the third molar shows the most. The general pattern seems to be a minimization of the anterior dimorphism, beginning with $\mathrm{P}^{3}$ but excluding the canine, and a maximization of the posterior dimorphism and dimorphism of the canine. $\mathrm{P}^{4}$, which showed the greatest difference in the gracile/robust comparison with gorillas, also shows a great deal of sexual dimorphism within the gracile and robust samples. These data verify Robinson's ('52) suggestion that the australopithecine $\mathrm{P}^{3}$ "behaves" as part of the anterior field since compared with pongids, the amount of dimorphism is reduced within the canine field while the $\mathrm{P}^{4}$ "behaves" as part of the posterior field.

\section{DISCUSSION}

I believe that the pattern suggests a great difference in female and male australopithecine body size, with the sig- 
TABLE 6

Sexual dimorphism in the maxillary dentition of four higher primate groups, expressed as the ratio of female to male mean areas, multiplied by 100

\begin{tabular}{ccccc}
\hline & Gorilla & D. africanus & $\begin{array}{c}\text { South African } \\
\text { australo- } \\
\text { pithecinc }\end{array}$ & $\begin{array}{c}\text { Living human } \\
\text { population } \\
\text { maximum }\end{array}$ \\
\hline C & 48.6 & 66.1 & 79.1 & 87.9 \\
$\mathrm{P}^{3}$ & 87.4 & 83.4 & 93.8 & 91.5 \\
$\mathrm{P}^{4}$ & 89.1 & 83.0 & 84.8 & 92.2 \\
$\mathrm{M}^{1}$ & 90.0 & 87.1 & 86.1 & 92.0 \\
$\mathrm{M}^{2}$ & 87.7 & 87.8 & 86.7 & 89.6 \\
$\mathrm{M}^{3}$ & 84.3 & 82.3 & 84.2 & 91.4 \\
\hline
\end{tabular}

Data are given for the maximum dimorphism found for a living group, the Murray Valley Australian ahorigines, based on data collected by C. L. Brace and used with his permission. The Dryopithecus africanus data is from Greenfield (72) with the addition of several other sexable specimens which he provided. The australopithecines represent the total sexable sample from South Africa, measured by the author and sexed by criteria discussed in the text.

nificant amount of posterior dimorphism resulting from the fact that the much larger males must masticate many more calories. The fact that this dimorphism begins at $\mathrm{P}^{4}$ is the result of the incorporation of the last premolar into the functional molar row, since the anterior position of the masseter acts to bring a maximum amount of vertical force through the posterior premolar-anterior molar region (Wolpoff, '74). That the same $\mathrm{P}^{4}$ difference characterizes the gracile/robust comparison suggests an average body size difference between these site-specific samples (Robinson, '72).

In contrast with the results obtained from calculation of the test statistic, table 5 shows that the ratio of australopithecine female to male means exhibit slightly more dimorphism than occurs in gorillas, beginning with $\mathrm{P}^{4}$ and moving posteriorly. Anterior to this tooth the dimorphism is less. While the significance cannot be directly tested, the australopithecines fit clearly into a general pattern of higher primate variation. Table 6 shows a comparison of the combined South African australopithecine sexable sample with a living human group with a maximum amount of sexual dimorphism, living gorillas, and a Dryopithecus africanus sample which may represent a common ancestor for gorillas and australopithecines. It is evident that the australopithecines have far more tooth size dimorphism than ever occurs in a living human group, and posterior to $\mathrm{P}^{3}$ even slightly more dimorphism than is observed in gorillas. However, the posterior dimorphism is closer to that of gorillas than to that of baboons (table 5) and in no instance does the australopithecine dimorphism exceed baboon dimorphism.

\section{A PHYLOGENETIC MODEL}

Using the dryopithecine sample as a possible example of the ancestral condition, the pongid trend seems to be one of decreasing posterior dimorphism and increasing canine dimorphism significantly. The reduction of posterior dimorphism is least towards the rear of the cheek teeth, and greatest anteriorly. Thus, the premolars have the greatest reduction (i.e., least dimorphism) while the posterior molars have the least reduction.

In the hominids the trend is almost exactly the opposite. Molar dimorphism is slightly increased, while canine and $\mathrm{P}^{3}$ dimorphism decreases significantly. The australopithecine condition is to have slightly more posterior dimorphism than $D$. africanus, and significantly less $\mathrm{P}^{3}$ and canine dimorphism. The gorilla pattern, on the other hand, is to have more canine dimorphism than $D$. africanus, but less posterior tooth dimorphism. As a result, the amount of dimorphism behind $\mathrm{P}^{3}$ of the 

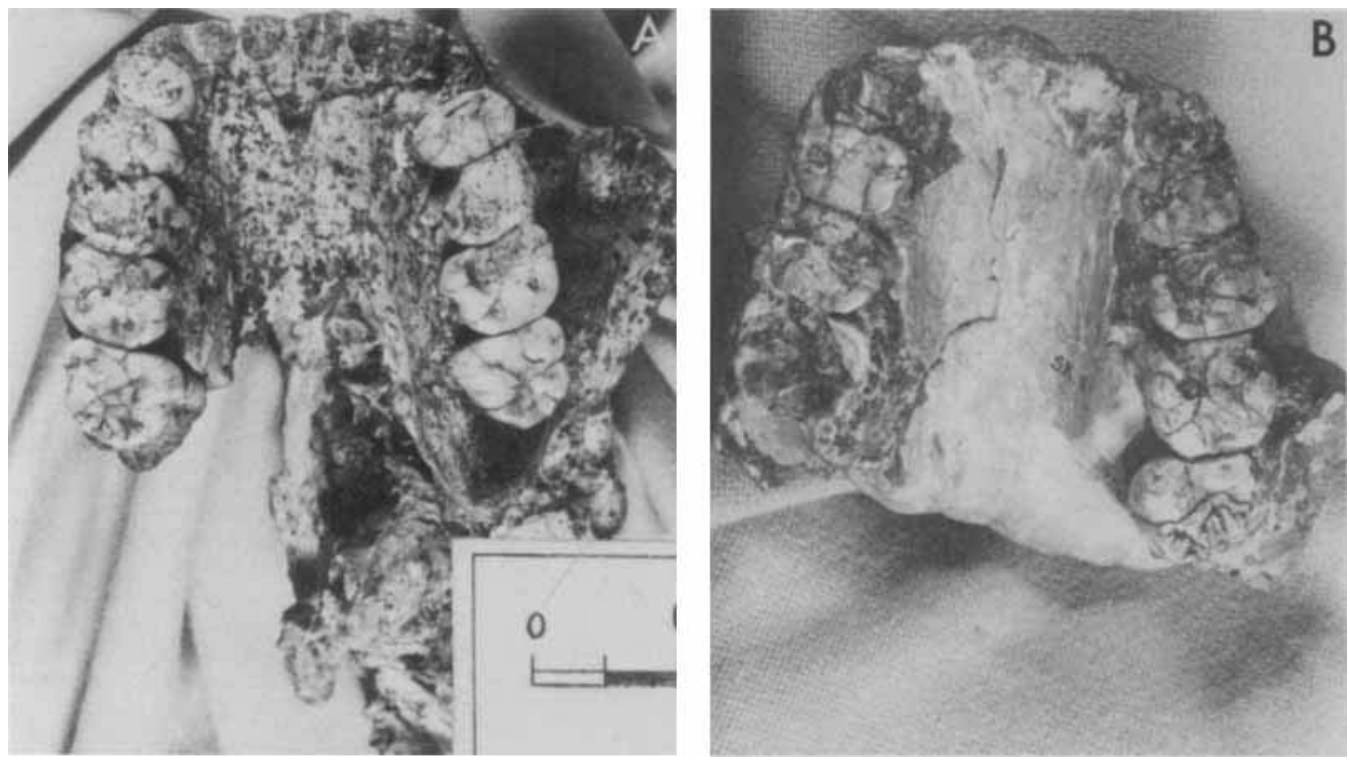

Fig. 2 Variation in maxillary tooth wear. The figure shows various contrasting patterns of tooth wear, as indicated by dentin exposure. All ages given are from Mann ('75).

(A) The Swartkrans maxilla SK 46 shows transverse cupping affecting the full occlusal surface of the premolars and first molar, and the mesial surface of the second molar. The age of this specimen is 34 years.

(B) SK 11 is slightly younger, 31 years. The pattern of dentin exposure shows an anterior-posterior element in the molars. The dentin exposed on $\mathrm{M}^{1}$ is lingual and mesial, and on $\mathrm{M}^{2}$ the mesiallingual corner is exposed first. At a more advanced age, SK-11 will resemble SK 46.

(C) MLD 9 contrasts with the above maxillae, although the age is also 34. A deep anteriorposterior groove involves the entire posterior dentition of this Makapan maxilla, suggesting a strong anterior-posterior component to mastication in contrast to the more lateral motions in the above specimens.

(D) STS 53, a younger specimen from Sterkfontein (26 years) shows a third pattern involving a much shallower molar wear gradient. In this pattern, flat wear reduces the posterior dentition to a flat, even surface with minimum difference in wear between the molars. Note that while the $\mathbf{M}^{\mathrm{l}}$ of this specimen resembles the $\mathbf{M}^{2}$ of SK 46 in terms of wear, the $\mathbf{M}^{2}$ is much more worn than the $\mathbf{M}^{3}$ of SK 46 . The gradient between these adjacent molars is much less than the gradient in the Swartkrans maxilla, and the flattening of the total occlusal plane extends to the third molar which is more worn than the third molar of SK 46 in spite of the more advanced age of the Swartkrans specimen. The contrast with the molar wear gradient of SK 83 (fig. 1) is even greater.

australopithecines is more than in gorillas, although less than in baboons.

These contrasting trends are the result of substantial adaptive differences that accumulated between the hominid and pongid lineages. Let us make the reasonable assumption that extreme canine dimorphism is related to behavioral dimorphism, reflecting significant role differences under a variety of different circumstances including dominance and defense (Washburn, '68; Washburn and Avis, '58), and that extreme posterior tooth dimorphism is a direct measure of body size difference. Both baboons and gorillas would then represent higher primates with substantial role differences and significant body size dimorphism. Perhaps the differences between them result from the adaptive differences faced by large terrestrial primates in a more forested as contrasted with a more open ecology. It would appear that $D$. africanus is more gorilla-like than baboonlike in body size dimorphism, and may show less role differentiation than either, perhaps a result of less complex social behavior in this 18-million-year-old anthropoid. The australopithecines come 

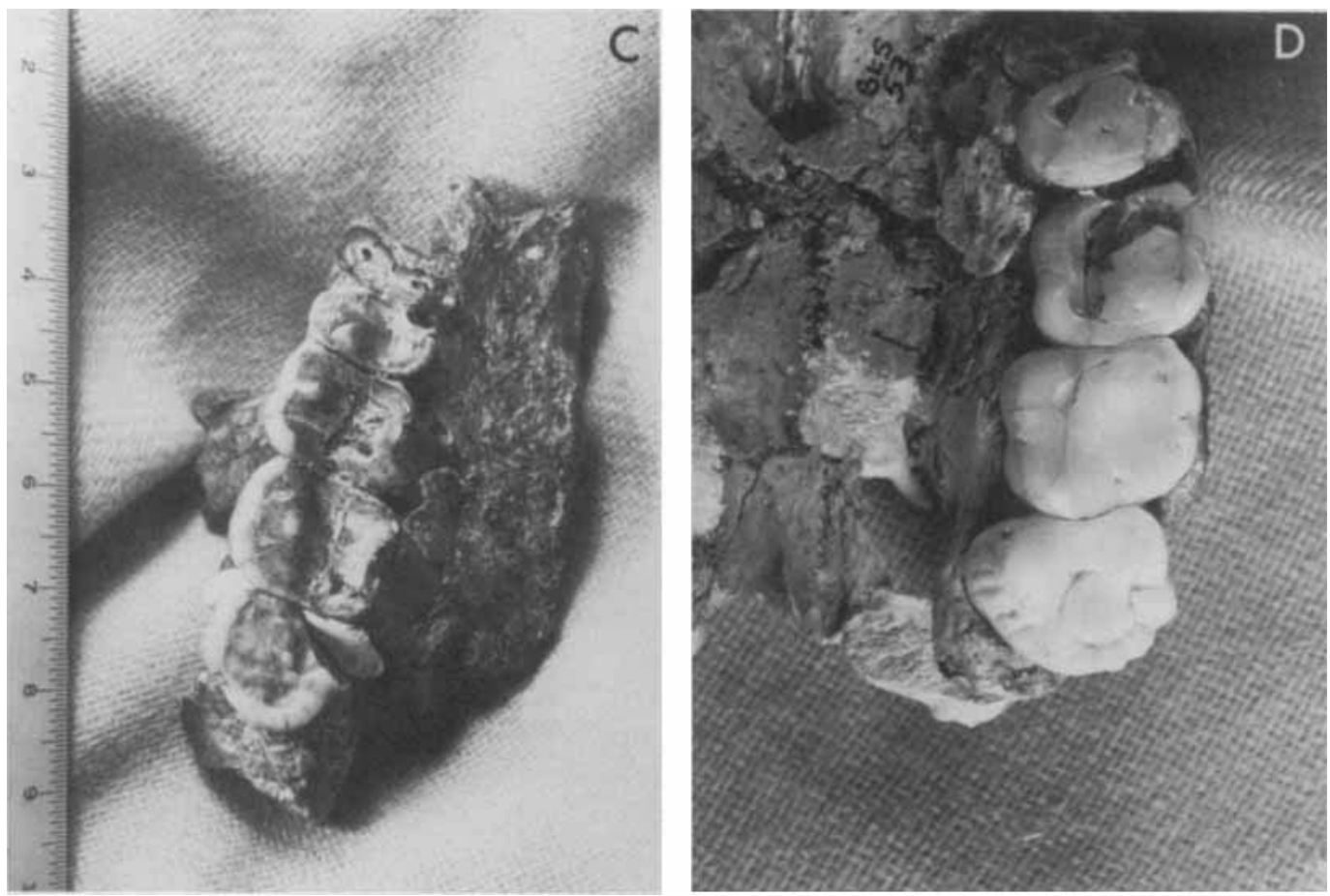

Figure 2

between the savanna and forest primate patterns for posterior tooth size dimorphism. However, I believe that the explanation for the significant posterior dimorphism is not directly ecological.

In the australopithecines, whatever the extent of the role differences between males and females was, the morphological change in the canine/anterior premolar complex suggests that tools had largely taken the place of the canines. While this would be expected to lead to a reduction in the differences in selection acting on male and female canines, at the same time it may well increase the difference in selection acting on body size dimorphism. With the increasing use of tools, selection might be expected to shift from producing large projecting canines in the males to producing males with especially large and powerful bodies. Size and power would become particularly advantageous with the replacement of the canines by clubs and rocks. The effectiveness of these simple weapons would be increased in direct pro- portion to the strength of the users (i.e., male hominids). Increased male body size and robustness would improve both the power and the distance over which these weapons are effective.

In sum, evolution of sexual dimorphism in the pongid lineage appears to be characterized by the development of more complex social organization and substantial role differences in the function of the canine premolar complex. In contrast, evolution in the hominid lineage would seem to differ as the result of tool use. The appearance of what must surely have been an at least equally complex social organization, with associated substantial role differences, did not lead to more canine dimorphism because of the replacement of certain canine functions by tools. At the same time there was a commensurate increase in body size dimorphism precisely because of the reflection of these role differences in tool use. It is tool use itself, rather than any specific ecological adaptation, which is hypothesized to account for the reduction in 
canine dimorphism and the increase in body size dimorphism as suggested by the dimorphism in the posterior teeth.

\section{SEXUAL DIMORPHISM AND VARIATION}

If the australopithecines have a level of sexual dimorphism in their posterior teeth that may exceed that of gorillas and approach that of baboons, the expected amount of variation within populations is rather greater than most workers have supposed. Only a few authors have suggested that australopithecine variation might best be compared with that of baboons (e.g., Brace, '73; Lauer, '75) because even modern human populations should not be expected to show equivalent variability.

However, the data presented here, indicating a level of dimorphism much greater than living humans, at least as great as gorillas, and for some of the posterior teeth cven approaching that of baboons, suggests that gorillas or baboons might be the best living primate model for australopithecine variability. The baboon model would seem more appropriate, since they are more wide ranging and polytypic than living gorillas. It is likely that australopithecine populations were also polytypic. One indication of this is the observed variation of specimens of the same sex, far too much variation to conceivably occur in one biological population. For instance, some males are considerably smaller than some females in virtually everything comparable except canine size. The simplest explanation is the existence of australopithecine populations of varying body size, all contributing to the sampling distribution. Another direct body of evidence suggesting polytypism is in the indications of dietary variation shown by the different tooth wear patterns (figure 2). These differences crosscut particular sites, and seem to have nothing to do with any of the proposed taxonomic schemes. The different wear patterns strongly suggest different dietary preferences, which might be among the causes of the populational differences. Therefore, the australopithecines appear to combine polytypic populations with notable dietary differences and commensurate tooth wear variation, even exceeding baboon polytypism, with a high level of populational variation due to marked sexual dimorphism. While the level of sexual dimorphism in gorillas is only somewhat lower, the living species is neither widespread nor significantly polytypic. If subSaharan samples of living humans are considered for comparison to maintain geographic equivalence, the level of morphological differences between populations is high, maintained in part because of competition between adjacent cultural systems. However, the greatly reduced sexual dimorphism within human populations leads to reduced populational variation. In all, the living primate that comes closest to matching the distribution of australopithecine inter- and intra-populational variation is the baboon.

\section{SUMMARY}

There is evidence of marked sexual dimorphism in the Lower Pleistocene hominids, as represented by the South African australopithecine sample. The dimorphism has nothing to do with the gracile/robust contrast, but rather occurs in both gracile and robust samples separately and identically.

The degree of posterior dimorphism is little modified from that observed in Dryopithecus africanus, and if this species can be taken to represent the ancestral condition, rather different trends characterize the evolution of sexual dimorphism in the pongid and hominid lineages. The evidence suggests that tool use, rather than any particular ecological specialization, is primarily responsible for the difference in hominid and pongid trends, leading to slightly increased posterior dimorphism with substantially decreased canine dimorphism in the hominids and decreased posterior dimorphism with increased canine dimorphism in the pongids.

Finally, the substantial variation that occurs within individual australopithecine sexes, in conjunction with other evidence suggesting differences in adaptive pat- 
terns, indicates that the australopithecines were an extremely polytypic taxon. Variation within populations due to sexual dimorphism, let alone idiosyncratic factors, matches that of any other primate and the mean male-female difference likely approximated $100 \%$ for body size. At the same time there seem to have been differences between populations which, on a morphological level, were at least as great as the morphological differences that characterize modern sub-Saharan African populations such as Bantu, Bushmen, and Pygmys. The australopithecines combine close to the primate maximum for variation within populations with the primate maximum for variation between populations. Consequently, it seems likely that the most appropriate species from which to draw analogies for early hominid variation can be found among the living baboons.

\section{LITERATURE CITED}

Bonnet, R. 1919 Die Skelete. In: Der Diluviale Manschenfund von Obercassel bei Bonn. M. Verworn, R. Bonnet and G. Steinmann, eds. Bergmann, Wiesbaden, pp. 11-185.

Brace, C. L. 1969 The australopithecine range of variation. Am. J. Phys. Anthrop., 31: 255 (abstract).

1971 Sex, inadequacy and australopithecine identity conflicts. Am. J. Phys. Anthrop., 35: 274 (abstract).

1973 Sexual dimorphism in human evolution. Yearb. Phys. Anthrop., 1972, 16: 31-49.

Brace, C. L., H. Nelson and N. Korn 1971 Atlas of Fossil Man. Holt, Rinehart and Winston, New York.

Garn, S. M., A. B. Lewis and R. S. Kerewsky 1964 Sex difference in tooth size. J. Dent. Res., 43: 306.

1966 Sexual dimorphism in the buccolingual tooth diameter. J. Dent. Res., 45: 1819.

Gonda, K. 1959 On the sexual difference in the dimensions of human teeth. J. Anthrop. Soc. Nip., 67: 151-163.

Greene, D. L. 1973 Gorilla sexual dimorphism and early hominid taxonomy. Symposia of the Fourth International Congress of Primatology. Vol. 3. Craniofacial Biology of Primates. pp. 82-100.

Greenfield, L. O. 1972 Sexual dimorphism in Dryopithecus africanus. Prim., 13: 395-410.
Holloway, R. L. 1970 Australopithecine endocast (Taung specimen, 1924): a new volume determination. Science, 168: 966-968.

Lauer, C. 1975 A comparison of sexual dimorphism and range of variation in Papio cynocephalus and Gorilla gorilla dentition. Prim., 16: 1-7.

Mahler, P. 1973 Metric Variation and Tooth Wear Patterns in the Dentition of Gorilla gorilla. Ph.D. Thesis, University of Michigan. University Microfilms, Ann Arbor.

Mann, A. 1975 Some Paleodemographic Aspects of the South African Australopithecines. University of Pennsylvania Publications in Anthropology 1 . University of Pennsylvania, Department of Anthropology, Philadelphia.

Mijsberg, W. A. 1931 On sexual differences in the teeth of the Javanese. Konink. Akad. Wetensch. Amst., Series B, 34: 1111-1115.

Pilbeam, D. R. 1972 Adaptive response of hominids to their environment as ascertained by fossil evidence. Soc. Biol., 19: 115-127.

Robinson, J. T. 1952 Some hominid features of the ape-man dentition. Off. J. Dent. Ass. S. Afr., 7: $102-113$

1972 Early Hominid Posture and Locomotion. University of Chicago, Chicago.

Robinson, J. T., and K. Steudel 1973 Multivariate discriminate analysis of dental data bearing on early hominid affinities. J. Hum. Ev., 2: 509-527.

Spiegel, M. R. 1961 Theory and Problems of Statistics. Schaum, New York.

Tohias, P. V. 1967 Olduvai Gorge. Vol. II. The Cranium and Maxillary Dentition of Australopithecus (Zinjanthropus) boisei. Cambridge, London.

Washburn, S. L. 1968 On Holloway's "Tools and teeth." Am. Anthrop., 70: 97-101.

Washburn, S. L., and V. Avis 1958 Evolution of human behavior. In: Evolution and behavior. A. Roe and G. G. Simpson, eds. Yale, New Haven, pp. 421-4.36.

Wolpoff, M. H. 1971 Interstitial wear. Am. J. Phys. Anthrop., 34: 205-228.

1973 Posterior tooth size, body size and diet in South African gracile australopithecines. Am. J. Phys. Antrhop., 39: 375-394.

1974 Sagittal cresting in the South African australopithecines. Am. J. Phys. Anthrop., 40; $397-408$

1975 Sexual dimorphism in the australopithecines. In: Paleoanthropology: Morphology and Ecology. R. Tuttle, ed. Mouton The Hague, pp. 245-284. 